\title{
Retirement in the Post-Revocation Context at One Canadian University: Experiences of Phasing and Delaying
}

Mia Quint Rapoport, Sara-Jane Finlay, \& Edith Hillan

University of Toronto

\begin{abstract}
This research study is a phenomenological exploration of academics from one Canadian university who either are participating in a phased retirement program or have delayed their retirement beyond the normal retirement age of 65. It is based on face-to-face interviews with 24 professors, male and female, between the ages of 55 and 69, from an array of disciplines. The results indicate that teaching may be a primary reason why academics choose to retire, that female academics seem to align their retirement plans with those of their partners, and that academics who postpone their retirement feel as though they possess a significant amount of respect within their fields. Since this research is based upon a small sample, it provides a starting point for future research studies, particularly concerning how gender affects the issue of academic retirement.
\end{abstract}

\section{Résumé}

Cette étude se veut une exploration phénoménologique des professeurs d'une université canadienne qui participent à un programme de retraite progressive, ou ont repoussé leur retraite au-delà de 65 ans, l'âge normal de la retraite. L'étude est basée sur des entrevues en personne avec 24 professeurs des deux sexes âgés entre 55 et 69 ans et provenant de diverses disciplines. Les résultats indiquent que l'enseignement peut être la raison principale pour laquelle les universitaires choisissent de prendre leur retraite, que les 
femmes universitaires semblent planifier leur retraite au même moment que celles de leurs partenaires, et que les universitaires qui retardent leur départ à la retraite estiment posséder une dose importante de notoriété au sein de leurs disciplines. Comme cette recherche est basée sur un petit échantillon, elle constitue néanmoins un point de départ pour de futures recherches, notamment sur la façon dont le sexe affecte la question de la retraite académique.

\section{Introduction}

Retirement, particularly as it transforms into what McDonald and Donahue refer to as the "new retirement" (2011, p. 3), is an important issue within Canadian universities. In their article entitled "Retirement Lost?" they discuss the current research concerning retirement in Canada. In so doing, they make two important points: the age of retirement is increasing (beyond the "normal retirement age" of 65) (p. 10), and new patterns of retirement are becoming available to older workers, thus making the "traditional model" of total retirement from the labour force at age 65 increasingly less realistic for academics (p. 11). At the same time, Clarke et al. (2009) cite inflation, competition, fiscal restraints, and expansion as transformative factors for Ontario universities, and identify faculty salaries as the "largest single portion of higher education costs." As a result of the revocation of mandatory retirement, faculty members are less likely to retire, thus "reducing the flexibility to lower costs through hiring junior replacements or by restructuring operations" (p. 111).

University administrators and planners have to balance the university's need for experienced academics who have high reputational value with the need for junior faculty who provide fresh ideas. They must also contend with changes in research fields, disciplines, and modes of inquiry-all of which are connected to the demographics of faculty members in the contemporary academy. The end of mandatory retirement at age 65 (which occurred between 2005 and 2006 at most universities in Canada) is changing this demographic picture. The present study took place at the University of Toronto, which publishes an annual report entitled Facts and Figures (University of Toronto, 2013); the report for 2012 found there to be just under 2,000 tenured and tenure-stream professors at the university, with the average age of a full professor being 56. According to a report supplied by the Office of the Vice-Provost Faculty \& Academic Life, there are 154 faculty members over the age of 65, and just under 500 are approaching their NRD (normal retirement date), i.e., 65. Currently, 43 faculty members are participating in the Phased Retirement Program (PRP), and to date, 94 faculty members have completed the program. Therefore, even with the success of the PRP, over the next 10 years there will be more senior academics on campus than ever before, which could affect administrative priorities.

It should be noted here that not all Canadian universities offer their tenured academics a phased retirement option. While other large research institutions-such as McGill (McGill University 2013), the University of British Columbia (University of British Columbia 2013), the University of Alberta (University of Alberta 2013), and the University of Western Ontario (Western University 2013) - do offer a similar phased retirement program to tenured and permanent faculty, other small and mid-size universities, such as York University and Ryerson University, do not. 
In this paper, we consider the experiences of academics on the cusp of retirementweighing their options, delaying beyond what is still referred to as the normal retirement age of 65, or "phasing" into their retirement. We use the word "Phasers" throughout this paper to describe this group of people, applying a phenomenological methodology. We explore the perspectives of male and female senior academics between the ages of 55 and 69 , from a range of disciplines at the University of Toronto, on the issues of retirement and their experiences of "being senior" in an organization that has changed dramatically over time.

\section{Previous Literature}

In the United States, mandatory retirement was revoked in the 1990s. Dorfman has conducted a number of studies examining the experiences of senior faculty members who have reached their NRD (Dorfman, 1992, 1997, 2002, 2009). As her research demonstrates, senior faculty members who reach their NRD display a strong commitment to their work. This fuels their desire to continue to work post retirement age. Furthermore, for many faculty members, retirement is a productive, active, and satisfying period of their lives. In her most recent article concerning professors working past the age of 70, Dorfman finds: "it is notable that many of the employed and retired faculty viewed the attitudes of their younger colleagues toward older faculty as mainly positive, negating ageist views of older persons as no longer contributing or productive" (2009, p. 1043).

Conversely, Kim (2003), using a human capital theory, found that faculty members who were less productive in their later years were more likely to opt for early retirement, particularly when financial rewards were offered. Firmin and Craycraft found, in their indepth but small-scale study, that professors who prepared for their retirement were more satisfied once they had retired (Firmin \& Craycraft, 2009).

In her study, McDonald (2006) found that retirement is a gendered phenomenon, in ways that mirror the experiences of female academics in general. Winston and Barnes (2007) have also considered the gendered nature of academic retirement. They examined the experiences of women faculty from the "baby boom generation" (those born between 1946 and 1964) to determine how these women define and anticipate retirement. As they write:

In our research, it became clear in analyzing these women's narratives that they were redefining the role of the retiree. Retirement was anticipated to occur when the individual was ready to assume the role rather than being linked specifically to age norms. Furthermore, retirement was to be an active period in life with some continuity between roles engaged in at work and those played after retirement. (p. 141)

It appears that for these women, the benefits of the "new" retirement are about choice and a gradual role redefinition, as opposed to an abrupt change from academic to retiree.

In order to retain valuable faculty members and to anticipate the needs of their workforce, many institutions have realized the concept of retirement has changed and have introduced phased retirement programs. Research conducted by Allen, Clark, and Ghent (2004) using data from the University of North Carolina's system and the Associa- 
tion of American University Professors (AAUP) Survey of Changes in Faculty Retirement found that phased retirement programs allowed universities to better cope with the sudden loss of valuable and experienced

"talent" while making room for fresh new scholars. Working with the same data set, Allen et al. (2004) concluded that phased retirement is a valuable program for institutions because it allows faculty members to retire closer to their normal retirement date. Phasing makes the process more manageable for both the institution and the faculty member, and it reduces the "nightmare" (p. 6) of losing faculty members who may begin lucrative consulting work while remaining on contract at the university. Based on the literature, the revocation of mandatory retirement in the United States and Canada has made it difficult for university administrators to plan and manage their professoriate. Phased retirement programs relieve some of the tensions that arise from the conflicting needs of academics and administrators.

Up to this point, no published research has explored the post-revocation context of retirement for Canadian university faculty members. However, Worswick (2005), anticipating the change to retirement rules, found that faculty felt mandatory retirement was a constraint. He suggested that when mandatory retirement was removed, faculty members would prefer having the option to stay on past age 65, but few would actually take this option. Likewise, Brys van Sluys (2005) predicted the actual age of retirement would not increase significantly. Writing in 2005 in Time's Up! Mandatory Retirement in Canada, editors Gillin, MacGregor, and Klassen explore some of the themes regarding the debate around mandatory retirement in Canada and challenge some of the conventional social and economic assumptions that support the policy. They devote two chapters to the specific context of the university in relation to mandatory retirement, since "academics have been the most active in questioning the rationale for retirement at a specified age" (p. 15). In one chapter, MacGregor argues that mandatory, or "forced," retirement is discriminatory and ageist, and links this to more contentious issues within the contemporary academy. He states, "[F]orced retirement cements the dominance of university administrators over faculty and also divides the faculty members on age/gender lines, weakening their collective influence" (p. 41). He concludes that mandatory retirement contributes to the breakdown of social relations in universities while providing virtually no benefits. He argues, "[T] compared to the benefits. Replacing a professor with a younger recruit yields only a small, short-term reduction in salary. However, this gain must be balanced against the loss of the older institutional knowledge and experience" (p. 43).

In a later chapter, Jean McKenzie Leiper's first-person account indicates that the NRD has particular implications for female professors. Many female academics begin their careers later in life and thus experience truncated career tracks. Not only are their pensions much smaller, but, as Leiper's account reflects, female academics may be less willing to retire at 65. Many of the arguments and ideas in the essays in Time's Up provide an essential foundation for the groundwork of this study.

\section{Methodology}

In his research, Stephen Weiland emphasizes the importance of collecting and examining the narratives of academic lives-the biographies of individual professors. He 
suggests these are important sources of information and data, arguing that knowing more about the career histories of mid-level and senior faculty reveals more about the nature and experience of working in higher education. As he states:

The study of higher education and faculty careers has used quantitative research in an attempt to achieve legitimacy. ... Biography can help us to see how individual lives mark decisive conjunctions of action and structure ... moments of structuring at which human agency encounters social possibility and can be seen most clearly as simultaneously determined and determining. (1994, p. 403)

Weiland's approach to the study of higher education is based on collecting academic narratives to understand the process of academic knowledge discovery, and it forms the underlying theoretical starting point for this paper. As such, in the design of this study we have examined the career histories of the research participants, since our aim, like Weiland's, is to contribute to a deeper understanding of the contemporary professoriate in Canada. However, in this study, our research is based on the self-perceptions of the participants and is thus slightly different than a retelling or a narrated biography. It is autobiography, not biography.

Despite this difference, Weiland's approach to research informed our choice to pursue a phenomenological research design for this study on academic retirement. We wish to introduce new forms of scholarship to the field of higher education. Phenomenology seeks to deconstruct and reveal a particular social phenomenon, based on how people perceive and articulate their experiences of it. In their introduction to qualitative research, Bogdan and Taylor explain how the phenomenological "perspective" $(1975$, p. 13) is a central starting point within many different forms of qualitative research. Their description provides a foundational definition of what phenomenological researchers try to attain:

The phenomenologist views human behaviour-what people say and do-as a product of how people interpret their world. The task of a phenomenologist, and for us, the qualitative methodologist is to capture this process of interpretation. To do this requires empathic understanding ... The phenomenologist attempts to see things from that person's point of view. (p. 14)

The authors then enumerate two offshoots of phenomenological research: symbolic interactionism and ethnomethodology. For Bogdan and Taylor, most qualitative research seeks descriptions of experiences of a certain social phenomenon as a way to understand it. Phenomenological research moves away from a "positivistic" (p. 2) approach, and as such is interpretive and exploratory. As they explain:

Qualitative researchers can study certain general processes in any single setting or through any single subject. They hope to observe and understand those general processes as they occur under specific circumstances. In a sense, then, all settings and subjects are representative of others. (p. 12)

As per phenomenology, we put forth not a theory but rather descriptions of a set of experiences that allow us to comprehend the underlying issues. This study illustrates the experiences of male and female senior academics at one Canadian university, who either are on the cusp of retirement, are phasing into retirement, or have postponed retirement. 
Thus, the two main social phenomena under investigation here are "being a senior academic" and "experiences of retirement"-the latter including its postponement.

\section{Study Context and Research Questions}

The revocation of mandatory retirement in Canada took place in 2006. As a result, some elements of the "new retirement" are occurring within the context of contemporary university culture. At the same time, many of the more traditional elements of retirement remain in place. Therefore, the phenomenon of retirement seems to be simultaneously traditional and new, much like the culture of contemporary academia itself.

As of 2009, there were 1,946 tenured or tenure-stream faculty members, approximately 136 full-time librarians, and 300 teaching-stream faculty. Just under 500 of these academics were over the age of 60 (University of Toronto, 2010). In the fall of 2011, there were 146 faculty over the age of 65, 40 women and 106 men. Twenty-eight of these were over the age of 69, (23 male, five female). As of 2013, 43 faculty members were participating in the PRP, and 94 faculty members had completed the program. The PRP allows faculty members to work a total of 150-200 percent over three years, including a provision to take a sabbatical during the phased period. Indeed, several of the participants in this study strategically arranged their phasing out plans to include a sabbatical during the year when they worked 100 percent. Senior academics that enroll in the PRP have one month to revoke their notice of intention to retire, although when the data for this study were gathered, none had done so. Recently, the university offered a Special Retirement Package (SRP), in which eligible faculty members, senior lecturers, and librarians receive one year of paid leave if they retire by a specific date. Just over 100 faculty members over the age of 60 have opted for the SRP.

This study examines retiring academics as well as academics who postponed their retirement beyond age 65. It was designed and initiated in 2010 within a specific social context. Four years had passed since the end of mandatory retirement, and the PRP, introduced in 2005, had turned out its first generation of "graduates." Senior academics were offered incentives to retire, while at the same time, many academics in that age bracket were chairing departments. Prior to the end of mandatory retirement, many senior academics at the university would have imagined retiring at 65. But when mandatory retirement was revoked, a new future was possible.

We wanted to answer a number of questions in our study. How did it feel for academics to phase into retirement? Did they feel marginalized by being in an intermediate state (if they saw it as such in the first place)? Were they treated differently by their peers? Did they feel the phased retirement program was fair? What changes would they have made, if any, to the program? Did they have grandchildren, life partners, caregiving responsibilities, or financial concerns? Were they anxious about retirement? If so, what were those anxieties related to?

We felt it necessary to examine not only academics who were retiring but also academics who had decided to postpone their retirement. We were curious. In this particular context, what were the mains reasons behind choosing to keep working past 65? Did they feel pressured to retire? Did they feel they possessed a higher status because of their seniority in their department, or was that slipping away as they got older? When would they retire? What were their peers doing, and how did this affect their own decisions, if at all? 
With each of the 24 senior academics, we recorded one-hour interviews in their offices. We then transcribed the interviews and coded the responses for themes. The results of our study are structured around the two categories of participants in our research sample: Phasers (those participating in the phased retirement program) and Delayers (those who opted to stay at the university after the age of 65 without declaring any intention to retire). Our paper begins with a description of each group, followed by a presentation of results, which we base on the themes that emerged from the face-to-face interviews. We first present the experiences of the Phasers, then the experiences of the Delayers, and we conclude with an interpretation of these experiences within the context of the contemporary university.

\section{A Description of the Participants}

The data for the study come from 24 face-to-face, semi-structured interviews with senior academics, 11 men and 13 women, from a variety of departments throughout the University of Toronto. The participants were categorized as either "Phasers" or "Delayers." Individuals in both groups were asked to respond to similar sets of questions. These began with a brief history of their career at the University of Toronto, including when they were tenured or made permanent. We asked the Phasers to describe the terms of their retirement program, how they had made their decision to enroll in it, their experiences of phasing, and how they felt they were perceived by others. We concluded by asking whether they would change the program if they could. We asked the Delayers whether they had any plans to retire, how their retirement plans had changed as a result of revocation, whether they would consider phased retirement, and about the academic activities in which they were involved. In addition to requesting a description of their careers, we asked both groups how they felt the university environment had changed since they began working there, and to provide their perspectives on younger scholars.

We recruited participants from a list provided by the Office of the Vice Provost Faculty \& Academic Life (OVP-FAL) at the University of Toronto. We defined eligible participants as faculty over the age of 55 or faculty who were participating in the phased retirement program. The OVP-FAL sent potential participants an email invitation in which they were asked to contact the researcher via email if they were interested in participating. The identities of the participants were not revealed to the OVP-FAL. We made efforts to recruit faculty members from a variety of disciplines and emphasized gender parity in the sampling. In order to maintain anonymity and confidentiality, all of the participants were assigned a pseudonym, and any identifiers-such as a participant's field or departmentwere removed from any direct quotations.

\section{The Phasers}

Seventeen of the participants, four men and 13 women, were phasing or planning to phase their retirement. Ten of these Phasers would complete the three-year program by the age of 65 , while five would complete it by 68 . Two of our respondents, both female, did not exactly fit into either of these Phaser categories. One such respondent, who was 69, "Sara," was a recent "graduate" of the PRP but was still doing research in her lab at the university, without remuneration. As she explained, "Well, I get my pension." Even 
though she was not still phasing and was "officially retired," we chose to include her in our sample because of her ability to speak to the questions of self-perception as an academic retiree. One of the respondents, 61-year-old "Rose," participated in this study even though she had not yet declared her intention to phase her retirement. While she had not signed any documents, she was "on the cusp of phasing." We thought that including her would provide valuable information that could speak to the process of deciding to phase into retirement. Rose described herself as "completely obsessed with weighing the pros and cons, and thinking about the matter." We felt that both of these anomalies would bring greater detail to our understanding of the issues in the study.

\section{The Delayers}

In this study, we refer to the academics who have chosen to remain at the university, with no plans to retire, as Delayers. This name makes sense from the point of view of administrators, who still hold the age of 65 as the benchmark for retirement. However, it did not make sense to the participants in the group, who did not see themselves as having postponed or delayed their retirement. From their point of view, NRD was an arcane concept. As one Delayer, "Robbie," put it, "65 is a totally artificial number ... dreamed up by the Chancellor of Bismarck in Germany in the $19^{\text {th }}$ century!" There were seven Delayers in this study: five men and two women. Out of the two female Delayers, "Sadie" worked on a part-time basis. She began her career in academia later in life and as a part-time employee was not eligible to phase her retirement. She considered herself semi-retired, and as such was "making the mental transition towards more of a mentoring role" and moving away from teaching in her department. Interestingly, her experience of "delaying" her retirement was different than the others in this study. We believe this contributes to a nuanced understanding of the phenomenon.

\section{Results}

We divide the results of this study into two main sections. In the first, we present the responses from the Phasers, based on themes that emerged from our conversations, and in the second, we present the responses from the Delayers. In the Phasers section, we describe their overall reaction to the phased retirement program and continue with the reasons they chose to retire and their experiences of phasing. In the Delayers section, we describe why they decided to work beyond their NRD, whether they had any sense of when they would ultimately retire, and whether they would phase out. In the conclusion of the study, we compare and contrast the two groups and provide our interpretation of the participants' experiences.

The results indicate that the gender of the participants was a factor in choosing a retirement plan. Although gender differences within the two groups were not a factor when the research study was designed, the analysis of the results indicates that the experiences of both phasing and delaying retirement are different for male and female academics. Thus, the results of this study are organized thematically and, where possible, also by gender.

\section{Introduction to Responses from Phasers}

The 17 respondents who phased their retirement were satisfied with the program. They thought that it made sense for them financially, and that it provided, as "Jasper" described, 
"good practice" for them to become accustomed to living on a lower fixed income and to become "socialized," as "Sophie" referred to it, "to the idea of retirement." As Seth described:

It's a very nice deal, and unless you're a person who thinks they are kind of immortal, like the gods of Olympus, I think it's almost an irresistible deal. I'm astonished, frankly, that more of my colleagues haven't taken it. But I waited until the last minute to take it.

"Kate" felt "very fortunate" to be able to phase out, because she was part of "one of the first cohorts" of professors to have access to this policy. She continues, "[I]t makes for a much softer landing. I have been feeling very much that it came for me at the right time." Our initial notion as we conceived of this study was of the marginalization or lower status that the Phasers might feel as they phased out, but the respondents here were pleased with the program. Plus, as Jasper explained, "none of my exact peers are phasing this year, but I expect that others from my department will. I know my chair has been considering it." Finally, several of the respondents in this study took a strategic approach in how they phased their retirement. Many took a sabbatical during one of the years of their program that accounted for 100 percent of their total allocation of 150-200 percent.

\section{Phasers' Reasons for Retiring}

The Phasers we studied cited the following reasons for taking retirement: responsibilities at home and in teaching, changes in their work environment, and inequities in the system. None of the Phasers cited caregiving-whether for parents, children, or grandchildren-as the reason they were retiring, although one Phaser retired because she or he had a partner who was ill. As we show below, the reasons varied for men and women.

Many of the Phasers cited teaching responsibilities as a factor in their decision to retire; however, male and female participants gave different reasons for why their teaching duties affected their decision. For some of the female Phasers, teaching had become too demanding. As 68-year-old Sophie described:

I think it gets hard to teach, I think it gets harder, than doing some of the other work. It's more physically demanding. I remember when I was chair, one of the people in my department retired at 63, saying something similar, that she could not deal with the teaching any longer, it was taking so much out of her. It took me a while to comprehend that through my own experience. If you are a good, conscientious teacher, you put on new courses, you revise the work, you're reading it yet again before you come in to the class, you're thinking of more ideas to work with the students.

And as 68-year-old Kate explained:

I really was tired of doing formal types of teaching. In [my volunteer work] I will hold workshops, but that's a different type of teaching. I don't have to grade people. I have never liked grading. I'll miss my contact with the students in some ways, but I won't miss doing formal teaching. 
A similar issue came up in our discussion with "Lilah," who complained about "inequities" in teaching loads throughout the university. Teaching for her was incredibly "intense and time-consuming," and the number of courses she had affected her other work. For her, it was "unconscionable" that some professors (such as herself) had full loads while others could "buy" out of teaching. She found this off-putting in terms of how the university was managed and felt like a "have-not" as a result of her full load. Furthermore, as she explained:

I guess there are some people who teach the same courses year after year; this is of course a mythology of the university, that there are some people that are, you know, giving the same lecture that they gave 30 years ago and they've got it typed up on papers, practically falling apart. In fields that are changing, in which the scholarship is building, you just don't do that.

Lilah had developed a sense of resentment over the way teaching was managed, which factored into her decision to enter the PRP. But for 63-year-old "Jennifer" it was the emotional investment of teaching that was a burden. She had earned tenure only 10 years before her early phasing and described how teaching left her feeling exhausted-not because it was physically demanding (as with the other respondents), but because, as she said:

I found my ability to focus deteriorating. Originally I thought it was because I stopped smoking, but then I realized it was an ageing thing. My work is so intense. I work closely with the students and it requires a lot of investment and I recently felt I can't keep it up. I want to do it part-time-one semester on, one off-so the phasing is the part-time.

Some of the male Phasers also cited teaching as the reason to phase out, but for them it was because they felt it restricted their schedules. "Adam," who was 64 and would complete his phasing by 65 , explained:

You know, I didn't mind the teaching per se. I don't mind the classroom at all, I quite enjoyed that. But the problem is it just locks up your time so tight. It's hard to work on other things. I do a lot of consulting. I have always had a knack for consulting that has driven all of my research. It's a choice of do you stay locked into teaching undergrads, because for two days a week you can't do anything else.

He worked in an applied field and planned on ramping up his consulting activities following his phasing out. Another 61-year-old male respondent, also from an applied field, felt the same way. He said, "I don't love teaching large classes. I love the research and want to do it more. The teaching takes up a lot of time, but I do love the students." Two other male Phasers cited teaching responsibilities as the main reason behind their decision to retire-not because they felt it was too demanding or that it tied up their schedules, but rather because they felt that the quality of students over time had deteriorated.

Some of the female Phasers also cited their husbands and partners as main reasons behind their decision to retire. As "Chloe," who has no children, explained: "I am looking forward to a little bit more time with my husband. I've worked 60 to 80 hours a week since I started at U of T." Her husband was already retired. "Rachel" made an agreement with her retired husband. She said: 
My partner-husband is three years older than I am and he's got funding barriers, so he lost funding about three years ago and hasn't been able to get it back. So we were discussing when it was that we would leave the university and were financially able to, and I guess too with the new retirement rules there's no actual penalty for retiring at 60 . So I started phased retirement when I was 57 so I would be fully retired a year and a half after my husband.

Sara, the academic who had completed her phasing, also considered her partner when she crafted her retirement plan. She said:

I wanted to go part-time because my husband is retired and we have a place in California where we go in the winter and he is quite adamant about not wanting to live in Toronto winters. Um, so there was this kind of conflict. I think if it wasn't for that, I probably would have stayed on.

She was sympathetic to the planning needs of the university and enrolled in phased as a way to achieve some sort of part-time schedule. When we spoke, Sara was still working at the university and was funded by some small, continuous grants. She explained that she was grateful for the lab space, though she knew it was precarious and that she could be asked to leave at any time.

There were other reasons that the academics chose to enter phased retirement, some even earlier than 65. Lilah said she felt "pressured to make a decision" before a sabbatical she was taking, and several Phasers, both male and female, felt simply that their careers were at an end. One of these respondents, 63-year-old "Mitchell," felt his field had changed in a way that he disliked and as a result, decided it was his time to leave. He said:

I feel like it's a good time to make my exit ... I feel like it is going in new directions and for me to hang in there and be teaching the next generation when I'm not really plugged in well to what this newer generation of scholars is into. And I think that's appropriate. It's time for the next generation to take over.

Rachel also felt that her career at the university was stagnating and was, simply put, "over." She said:

My career is the work that I do with my graduate students and the bench research. I have been privileged to have really wonderful graduate students. I've always had funding from [a major granting organization], and I was very fortunate that the last full round, my grant was renewed. I recognized that I wasn't going to be able to renew it again. I wasn't recruiting graduate students, or at least the type of students that I wanted to work with. So I decided I could afford it and it was time to exit with dignity.

The sense of exiting with dignity was echoed in another Phaser's responses. "Mary," an academic librarian, explained:

I have had enough of working. I have a life outside. I'm a [mentions her hobby]. I teach that, I write, I give courses. It's just that I really wanted to do that. My husband died seven years ago, and since then, my whole outlook on life has changed. I just thought well, I want to do something different. 
As a librarian, she had seen her organization change dramatically over the past decade. While she didn't feel that these changes were negative, and felt she had embraced the changes, she did feel somewhat "outside" of them.

The Phasers did not struggle with their decision, although many respondents described feeling its weight. As Adam said, "It was definitely ... I mean, you signed on and that was it. There was no going back." And, as Sophie recounted, "Well, I guess that once you're locked in that the whole thing is irreversible. You can't do any further negotiations and you can sort of hear the door clang shut. I haven't regretted it." And finally, Chloe explained, "it was a hard thing for me to sign, it was. And I did not discuss it with anyone. The only person I discussed it with was my husband." "Jasmine," who was phasing out early, explains:

I thought about it for a whole year. Was I? Was I not? I was and I wasn't. Everybody said, “Oh, you're crazy, don't do it, because you know you won't use it, you'll just get paid less." I was quite anxious about it, because it's irrevocable; it really made it feel significant.

It was the irrevocability of the decision that was making Rose, who was on the cusp of phasing, hesitate, even though she had a complete vision for her retirement. Finally, "Cynthia," who was also retiring early, was critical of the fact that the phased retirement plan was not more flexible. She envisioned a program that would allow professors to exit and enter the workforce over the course of their careers. She felt this would enable more flexibility and work-life balance. As she explained:

I wish it were over a longer period of time and generally more flexible. So that you could do it at different points in your career without the kind of financial penalties that I experienced through my part-time work, or fewer financial penalties, I guess.

She was not the only woman to feel this way: Rose, who was on the cusp of retiring but hesitating because of its irrevocability, Sadie, who was postponing her retirement because she had a part-time arrangement, and Sara, who was a graduate of the phased program, all suggested that a part-time or flexible option would be desirable for senior academics. In some ways, phasing was a way for them to achieve some sort of professional flexibility later in their careers. This was precisely the case for Jennifer, who said, "That is why I am doing phased. That is, really; the phased is the part-time."

\section{The Delayers: Understanding More About Why Academics Postpone Their Retirement}

In contrast to the Phasers, the seven academics involved in this study who delayed their retirement felt they were still immersed in their work. They also reported that they still held a tremendous capacity for adapting to new ideas, methods, and technologies. The portrait they painted of themselves was not that of the stereotypical ageing faculty member. The Delayers were fascinated by the work their graduate students were doing, admitting that in their own early careers, they had not displayed the same level of sophistication. James, who was 65 and had no plans at all to retire, felt he was at the height of his career and explained that he was finally unhampered by the "unruly, timesucking" administrative tasks of university life. He said: 
Although it's not like it used to be-I used to stay up writing until 3 or 4 am, I don't have the same stamina as I used to. But it's fuller now and I am enjoying it more than ever before. I keep on getting more grant money, so I feel it's alright for me to continue.

When we asked him when he saw himself retiring, he responded, "I'll feel it when it's over. If I were to measure, I would say when I produce only one or two papers in a year. That's a slowdown for me." He also addressed the need to create space for younger scholars. "I don't feel I need to open up a spot for younger scholars. I am doing more for the university via my work than a younger scholar. Were this not the case, I would retire." One of the main differences between the Phasers and the Delayers who participated in this study was that the Delayers felt they still possessed a great deal of continuous academic productivity. When she turned 65, "Connie," who was approaching 70, felt she was

highly engaged in everything. I just started getting invited everywhere to be on commissions, keynote speaker, I was working with these great doctoral students, terrific colleagues. The work was just like, you know, you slag all your life to get to a point where people are actually using what you, in a professional program, you know you don't only want to be publishing. You want people to actually be using the ideas. So people were actually getting interested in using the ideas in policy and program. That was a major reason-my research was really peaking.

Thus, retirement at 65 was not an option for Connie, though she also felt strongly that "if you're not highly productive, you have no right to stay." She said, "I am highly critical of mid-career faculty who are not pulling their weight." She felt that, at 69, she was at the very centre of her field and the peak of her career. She also raised the gender issue, describing how she came to her career late and as a result was experiencing her success at a later age, stating, "In my thirties, I really said this is not enough, so I first went back part-time and then went back full-time. Now when I look at retirement, my attitude is, why would I go back to what, in my 30s, I was getting away from?” The difference between Phasers and Delayers may be based on their self-perception as someone with or without many productive years left in academia.

Many of the respondents, in both the Phaser and Delayer groups, felt strong attachments and responsibility to their academic field of study. The Delayers were convinced that they ought to stay as long as possible, for fear they would not be replaced. "Mark," who was 69, had planned on retiring at 65, which he felt was the "right thing to do for the university," but decided not to because it was not "right for his department." He felt that his retirement would leave a "gaping hole" in the department. He said that everyone had worked hard to develop an "intensely communitarian spirit," and while "[he] wouldn't say we are friends, since we don't see each other socially, but we really help each other out." He was skeptical about whether the university would replace him if he retired, as he was aware of the current financial climate. At the same time, he admitted he would consider a "seat sale"-a deal where professors are provided with extra compensation in return for their imminent retirement-were one offered over the next few years. We also spoke with "Jack," another respondent postponing retirement, who also said that the idea of succession was an important factor in his retirement decision-making. He took issue with the 
word "succession," which sounded too "egocentric." After some thought, he said, "The best word I can come up with is 'continuation.' The problem is not one of personally going on forever, but wanting to see what you have contributed to continued." It appears some of the reasons academics postpone retirement may include their belief that they are still productive, their perceived status, and their strong attachment to the department where they worked for many years.

Whereas teaching was a main reason the Phasers chose to retire, it was not an issue for the Delayers. Two Delayers in this study taught large undergraduate courses and reported that they enjoyed the teaching. One Delayer proudly recounted how, with the help of a younger colleague, he had recently overhauled his pedagogical style, moving from lectures combined with assignments to a more "experiential pedagogy involving group work." He said, "It was incredibly successful and I just couldn't believe it." We found that attitudes toward teaching were a point of contrast between our two respondent groups. When designing future studies regarding senior academics, focus should be placed on their attitudes to and activities involving teaching.

Another issue raised by three of the male Delayers was how retirement would affect their financial situations. (In contrast, none of the female respondents in either category suggested that their financial situations were at all a concern.) Accruing salary to contribute to their pensions was part of why these three of the Delayers chose to postpone their retirement. As Jack, who has four children, explained, "[C]learly, I would like to have a higher pension but so, um, I think the answer is that it is not a dominant issue, but it is not a negligible issue either." "James" had a similar response:

[A]s a professor, all of my life, I have had a comfortable life. But it's limited. And I want to be able to hand something substantial off to my children. So finances definitely factor into my reason to postpone my retirement. I'm not ready for a limited income.

Finally, "Robbie" explained that since he began his career at the university later than most, he wanted to contribute to his pension for as long as possible. He stated, "I feel almost semi-retired already, so why take the final step, because the pay is better than pension."

\section{Concluding Remarks}

This phenomenological study of 24 senior academics who were either participating in the PRP at the university or had postponed their retirement beyond their NRD is the first of its kind, not only because it is one of the few qualitative pieces describing the Canadian context, but also because it occurs in the post-revocation context. At the same time, this study is limited: the research sample is small, unbalanced (since it includes more "Phasers" than "Delayers"), and involves only one university. However, we would argue that there is great value in knowing about the difficulty in researching this topic, since problems in designing and carrying out the study are themselves informative. For example, we made many efforts to recruit Delayers within our time frame, but few volunteered. Our research showed that many Delayers were simply too busy and too active to have time to participate in our study. However, academics whom we classified as Phasers 
were more enthusiastic. They wanted to talk about their retirement, their choices, and their academic careers. It was as if our interviews provided a way for them to mark the closing of a chapter of their lives.

This study is an important first step for further studies in this area. It contributes to the available knowledge of research concerning the contemporary Canadian professoriate as well as the issue of contemporary retirement in academia. We found, as we coded our data, that gender differences between the participants provided a strong indicator of their attitudes to retirement. While our sample size was too small to provide conclusive evidence, we noticed that some of the responses to our questions followed traditional gender dynamics. For example, the female academics described teaching as too demanding to continue and were made tired by it as a result (though not tired of the teaching itself). From this, we wondered whether perhaps female academics become involved in their teaching in a different way than male academics. The male Phasers, in contrast, wanted to retire from teaching either because they wanted to free up time in their schedule or because they were disenchanted with their students. We see an important difference here-one that could be pursued in a study that looks specifically at gender and teaching in the academic context. The female Phasers, furthermore, were crafting their retirement plans to follow their partners', while the male Phasers in this study rarely mentioned their partners as important in their plans. Further study is needed to understand why, although we hypothesise it is because female professors were more likely to discuss these plans with their partners. But it is an interesting insight into gender dynamics in universities, particularly as contemporary universities work towards supporting more equitable gender relations.

\section{References}

Allen, S. G. (2004). The value of phased retirement. NBER Working Papers, 10531. Cambridge, MA: National Bureau of Economic Research.

Allen, S. G., Clark, R. L., \& Ghent, L. (2004). Phasing into retirement. Industrial and Labor Relations Review, 58(1), 112-127.

Bogdan, R., \& Taylor, S. J. (1975). Introduction to qualitative research methods. New York, NY: John Wiley \& Sons.

Bourdieu, P. (1996). Homo academicus. Cambridge, UK: Polity Press.

Clark, I.D., G Moran, M.L. Skolnik, and D. Trick. (2009). Academic transformation: The forces reshaping higher education in Ontario. Montreal and Kingston: Queen's Policy Study Series, McGill-Queen's University Press.

Dorfman, L. T. (1992). Academics and the transition to retirement. Educational Gerontology, 18, 343-363.

Dorfman, L. T. (1997). The sun still shone: Professors talk about retirement. Iowa City, IA: University of Iowa Press.

Dorfman, L. T. (2002). Stayers and leavers: Professors in an era of no mandatory retirement. Educational Gerontology, 28, 15-33.

Dorfman, L. T. (2009). Ten years later: A follow-up study of professors still working after age 70. Educational Gerontology, 35(11), 1032-1045. 
Firmin, M. W., \& Craycraft, A. (2009). Life meanings for past and present: Case studies of four retired faculty. Educational Research Quarterly, 32(4), 17-35.

Gillin, C. T., MacGregor, D., \& Klassen, T. (Eds.). (2005). Time’s up! Mandatory retirement in Canada. Toronto, Canada: James Lorimer \& Company.

Kim, S. (2003). The impact of research productivity on early retirement of university professors. Industrial Relations: A Journal of Economy and Society, 42(1), 106-125.

McDonald, L. (2006). Genedered retirement: The welfare of women in the "new" retirement. In L.O. Stone (Ed.), New frontiers of research on retirement. Ottawa: Statistics Canada.

McDonald, L., \& Donahue, P. (2011). Retirement lost? Canadian Journal on Aging / La Revue canadienne du vieillissement, 30(3), 401-422.

McGill University. (2013). Early and phased retirement policies and procedures. Retrieved from https://www.mcgill.ca/apo/category/tags/retirement

University of Alberta. (2013). Retirement options for continuing academic staff. Retrieved from www.hrs.ualberta.ca/MyEmployment/ /media/hrs/Benefits/ LifeEvents/Retirement/Academic/Retirement_Tipsheet.pdf

University of British Columbia. (2013). Easing into retirement. Retrieved from http:// www.hr.ubc.ca/faculty-relations/retirement/easing-into-retirement/

University of Toronto. (2010). Facts and figures 2010. Retrieved from http://www. utoronto.ca/_shared/assets/UofT_2010_FactsFiguresReport_G4323.pdf

University of Toronto. (2012). Facts and figures 2012. Retrieved from utoronto.ca/ about-uoft/quickfacts/factsandfigures/Facts Figures_2012.htm

van Sluys, B. (2005). Current trends in retirement: Implications for the Canadian university community. Lethbridge, Canada: University of Lethbridge Faculty Association.

Weiland, S. (1994). Writing the academic life: Faculty careers in narrative perspective. Review of Higher Education, 17(4), 395-418.

Western University. (2013). Western retirement guide. Retrieved from http://www. uwo.ca/hr/form_doc/pension/doc/plan_info/retirement_guide.pdf

Winston, N. A., \& Barnes, J. (2007). Anticipation of retirement among baby boomers. Journal of Women \& Aging, 19(3/4), 137-159.

Worswick, C. (2005). Mandatory retirement rules and the retirement decisions of university professors in Canada. Analytical Studies Branch Research Paper Series, Statistics Canada, catalogue no. 11Foo19MIE - No. 271. Ottawa, Canada: Ministry of Industry. Retrieved from http://publications.gc.ca/Collection/Statcan/11Foo19MIE/11F 0019MIE2005271.pdf

\section{Contact Information}

Mia Quint Rapoport

Ontario Institute for Studies in Education

University of Toronto

mia.quint@utoronto.ca 
Mia Quint Rapoport received her PhD from the Ontario Institute for Studies in Education at the University of Toronto where she studied contemporary higher education. Her thesis, which explored the development of open source software in higher education, won the 2011 Geis Award from the Canadian Society for the Study of Higher Education. Between 2011 and 2013, she served as a post-doctoral fellow at the University of Toronto's Office of the Vice Provost, Faculty \& Academic Life.

Sara-Jane Finlay completed her doctorate in sociology at Loughborough University in the United Kingdom. She held faculty positions at Southampton and Plymouth before returning to work in Toronto. In 2010 she became the Director, Faculty \& Academic Life. Her responsibilities include the operational and management priorities of the Office of the Vice Provost, Faculty and Academic Life as well as providing leadership across the University of Toronto campuses in the development of policy and process related to academic human resources, academic policy, and academic planning.

Edith Hillan is currently Vice-Provost Faculty \& Academic Life at the University of Toronto. Her academic appointment is held in the Faculty of Nursing, where she still teaches and supervises graduate students. Edith Hillan holds an MPhil in Law \& Ethics in Medicine from the Faculty of Law, University of Glasgow (1994), a PhD from the Faculty of Medicine, University of Glasgow (1990), and an MSc from the University of Strathclyde (1983). 